\section{Fake it till you make it: imagined social capital}

The Sociological Review 2017, Vol. 65(I) 52-66

(C) The Author(s) 2016

Reprints and permissions: sagepub.co.uk/journalsPermissions.nav DOI: 10.1 I I I//467-954X.12368 journals.sagepub.com/home/sor

@SAGE

\author{
Greti-Iulia Ivana
}

Uppsala University, Sweden

\begin{abstract}
Social capital is one of the most widely used (in both scholarly and non-scholarly contexts) and one of the least critically examined concepts in Bourdieu's framework. This article aims at questioning the objectivist standpoint from which the concept of social capital has been developed, by looking into the interpretative processes which shape it. In doing so, it proposes a new understanding of the notion of imagined social capital, which has gained prominence in the literature of the last several years. The contribution of the current paper lays in elaborating on the ways in which the existing notion of imagined social capital can be put in dialogue with Bourdieu's work and in introducing the overlooked, yet fundamental question of otherness into the debate on imagined social capital.
\end{abstract}

\title{
Keywords
}

Bourdieu, hermeneutics, imaginary, meaning, social capital

Throughout scholarly literature, social capital is understood as an attribute which is personal, but which invokes a relational dimension, the glue which creates communities or an intrinsic element of social stratification. It may be changing and it may depend on many people or on large-scale social structure. Yet, it always captures an objective reality. It refers to actual bonds between actual people, to existing, observable, measurable patterns of stratification, to communities and their social importance. The aim of this article is to question the taken-for-grantedness of social capital as objective reality and to ask about the meaning construction processes behind it.

The underlying assumption on which the concept of social capital currently stands is that although we might read social relations in a particular manner, our reading is an added layer, not a core factor in the construction of social capital. This claim is most clearly questionable on several grounds. On the one hand, each bond is a universe of emotions, mutual interpretations of interactions, expectations, doubts and contradictions.

\section{Corresponding author:}

Greti-lulia Ivana, Uppsala University, Department of Sociology, Engelska parken, Thunbergsv. 3H, Box 624, 75126 Uppsala, Sweden.

Email: greti-iulia.ivana@soc.uu.se 
Questions about whether the other is a reliable contact, whether he/she would be willing to help in a given context, the length to which particular bonded people expect to go for each other, the level of solidarity in extreme situations and many other such doubts are difficult to answer even for participants in relatively stable and well-defined bonds. On the other hand, social capital is different when seen from the inside in comparison with the outside perspective. Accepting the faulty premise of a quantifiable or at least estimable quality to one's social capital, we are still left with the conclusion that the subject in question is the only person with an accurate sense of his/her 'real' social capital. Yet, the position of that person in the social field will be highly dependent on interpretations and assessments done by others. Furthermore, in relation to the exterior assessment of one's network of relations, it must be noted that social capital has very few symbolic markers. If economic capital is displayed symbolically through the possession of goods or the use of expensive services, cultural capital through diplomas and certificates, nothing similar exists for social capital.

Bearing these considerations in mind, this article is aimed at exploring the concept of social capital as a less reified social construct. In order to achieve this aim, I will discuss several points in Bourdieu's account of social capital, both separately and by comparison with other theories generally viewed as emblematic for this topic, such as Coleman's and Putnam's. With respect to Bourdieu's social capital I explore, following Crossley (2001) and Bottero and Crossley (2011), the implications of a shift from the analysis of objective relations between different positions within the social field, to the analysis of actual social relations in their unfolding. With respect to Coleman and Putnam, I insist, following Smith and Kulynych (2002), on the importance of adding insight about power struggles and the strategic dimension of networking.

After these clarifications of my position in relation to the literature on social capital, I will turn to the idea of imagined social capital. While the concept has been coined by Quinn (2005), my use of it differs from hers in several points. Thus, the greater part of the text will be dedicated to elaborating on the construction and use of imagined social capital, as well as on the conditions which shape it and the consequences it favors. Last but not least, I will discuss the ways in which such imagined social capital contributes to everyday life understandings of the field and of social structure.

\section{Social capital - a look back}

As Putnam (2000) points out, the first use of the notion 'social capital' to capture dimensions of sociability and bonds belongs to Lydia Judson Hanifan, a state supervisor of rural schools. Since the term was introduced in 1916, it featured occasionally in various texts, but the first elaborated and complex analysis of the concept was produced by Bourdieu. He defines social capital as 'the aggregate of the actual or potential resources which are linked to possessions of a durable network of more or less institutionalized relationships of mutual acquaintance or recognition' (Bourdieu, 1985: 248). His view of the concept is dominated by his interest in the benefits derived from membership in certain groups and in the deliberate courses of action aimed to ensure that belonging. For Bourdieu, the distribution of social networks is not contingent and one must invest effort and strategies into obtaining a position in a network, which is a resource in itself. 
However, in relation to the acquisition of social capital, Bourdieu's perspective is far from being exclusively voluntaristic. To him, social capital is a tool in the hands of the powerful, reproducing social inequality and ensuring the distance between social groups. In this sense, although social capital is acquired through different processes than economic or cultural forms of capital, it continues to be strongly linked to them, as it serves to perpetuate and legitimize the same structural gaps. Going beyond the strategic component of gaining social capital, in Bourdieu's analysis, bonds, networks, membership in and exclusion from certain groups, are all organized in terms of social class. Coming from a family of entrepreneurs, Bourdieu would argue, will make one statistically more likely to have friends with similar levels of economic capital. Thus, while there are ways in which social capital can be negotiated by social actors, the success of these negotiations will be dependent on the positions of the actors in the social field. Bourdieu talks about the group's internal tendency of maintaining homogeneity within itself and distance from the others:

When, as in modern societies, families lose the monopoly of the establishment of exchanges which can lead to lasting relationships, whether socially sanctioned (like marriage) or not, they may continue to control these exchanges, while remaining within the logic of laissez-faire, through all the institutions which are designed to favor legitimate exchanges and exclude illegitimate ones by producing occasions (rallies, cruises, hunts, parties, receptions, etc.), places (smart neighborhoods, select schools, clubs, etc.), or practices (smart sports, parlor games, cultural ceremonies, etc.) which bring together, in a seemingly fortuitous way, individuals as homogeneous as possible in all the pertinent respects in terms of the existence and persistence of the group. (Bourdieu, 1985: 249)

Furthermore, for Bourdieu the various types of capital are not only connected, but fungible. As Portes (1998: 4) highlights, in Bourdieu's framework, all types of capital, including the social, can be reduced to economic capital. In concrete terms, by being well connected, one can gain access to information and resources to increase his/her wealth or he/she can be given official recognition (cultural capital), which in turn translates into increased economic capital as well.

A different, but equally refined regard on social capital comes from Coleman (1988, 1991). Despite its incontestable merits, however, Coleman's work is often difficult to follow because of his tendency to collapse various dimensions of the concept into the same category. This shortcoming is tackled by Portes (1998) and Tlili and Obsiye (2014) who highlight the fact that in Coleman's conceptualization, social capital refers to the mechanisms which generate social capital, the outcomes of social capital, the capital individuals accumulate by virtue of their relations, the characteristics of the group or community and social norms. As a result, this framework obscures the relation between these aspects and the ways in which they are articulated in social organization. The other common critique towards Coleman's theory is the disregard for structural elements in the distribution of social capital (Croll, 2004; Gowan, 2010; Lareau, 2002; Morrow, 1999). The starting point in Coleman's analysis is a functionalist dimension of social capital. In his understanding, this concept will contribute to overcoming the structure versus agency debate by focusing on the functions fulfilled by social relations in helping social actors achieve their goals. While insisting on how relations will materialize into capital for 
individuals who are involved in them, Coleman understates the importance of class and of belonging to particular social strata in the building and maintaining these relations. The same can be said about Putnam, whose core premises are very similar to Coleman's. As Smith and Kulynych (2002: 158) synthetically and compellingly put it, drawing on Parsons' (1957) positive and zero-sum conceptions of power, Coleman's approach is centred on the 'power to', whereas Bourdieu's revolves around the 'power over'.

Given the systematic theoretical framework in which Bourdieu develops the concept of social capital and given the plethora of notions he mobilizes when discussing social relations, their benefits and structural limitations, this text will employ Bourdieu's conceptual apparatus. Nevertheless, for all the sharpness and lucidity of Bourdieu's analysis of social structure, he is, perhaps more so than Coleman, prone to painting an objectivist image of the dynamics of social capital. In his writings, Coleman often refers to the individuals who take part in the relation, the most likely ways in which they construct meaning for the contexts they are in or whether they trust each other. So, despite not elaborating on the hermeneutics of accumulated social capital, he does look into the interpretative dimension of the concrete relations on which that capital is based. In the case of Bourdieu, on the other hand, the concern for structural aspects has constantly overshadowed the attempts to account for subjectivity. As Jenkins puts it, 'it is difficult to know where to place conscious deliberation and awareness in Bourdieu's scheme of things' (Jenkins, 1992: 77).

There is, of course, a well-documented critique of Bourdieu's over-emphasis on social reality as objective and on social forces which shape not only the actual but also the possible (Atkinson, 2010; Alexander, 1994; Halle, 1993; Lamont, 1992; Widick, 2003; Adams, 2006; Kogler, 1997). These authors make little reference to social capital itself, but they discuss habitus and the position one occupies in the social field. However, for Bourdieu, a certain distribution of various types of capital is likely to translate into belonging to a certain class and into the development of a certain habitus, which in turn will impact the place one has within the social field. This process is circular, hence making habitus a structured and structuring structure (Bourdieu, 1990). In light of the cohesion and interconnectedness of the different parts of Bourdieu's theory, it must be said my concern with objectified social capital stems from the same ontological root as the texts denouncing the deterministic accents of habitus. As Crossley (2001, 2008, 2009) and Bottero and Crossley (2011) highlight, Bourdieu's theory is not deterministic in its core, but it does require shifts in emphasis in order to avoid appearing like a substantialist account of social structure. In this respect, King (2000) examines the disagreement between Bourdieu's commentators over whether his theory is a sophisticated structuralism or a step towards overcoming the structure-agency dichotomy. In King's view which is fully embraced in this article, the significant differences in reading Bourdieu stem from the substantial contradiction between habitus and the theory of practice. While he agrees habitus, which is an objectivist concept, takes up more of Bourdieu's work, making it more vulnerable from the standpoint of hermeneutics, he also insists on the fact that 'practical theory' is not plagued by the same problems as habitus. Despite the examples discussed by King (2000) to support the argument about the relational and fluid character of the social world in Bourdieu's practical theory and despite his attempt to circumscribe the objectivist accents in Bourdieu's work to habitus, concepts such as social field, class, 
capitals, 'the symbolic' (which, as Evens, 1999: 19 points out, is always in the service of capital), and social reproduction illustrate the same tendencies habitus does.

One path towards overcoming the critique of objectivism and materialism (Evens, 1999), Bottero and Crossley (2011) argue, implies questioning the point of view from which Bourdieu analyses social relations. Namely, Bourdieu rejects social network analysis and symbolic interactionist approaches for getting too close to their empirical object of study and missing the structures underlying the apparent diversity and chaos. His solution is to focus on social relations not as empirical subjective ties, but as interconnections between structurally established positions. This explains why there is little mention of subjective meaning construction or of the interpretative frames used by the social actors in Bourdieu's depiction of social relations. Coleman (1988: 102) was writing: 'If A does something for $\mathrm{B}$ and trusts $\mathrm{B}$ to reciprocate in the future, this establishes an expectation in A and an obligation on the part of B.' A and B are people in this example. Had this phrase been written by Bourdieu, A and B would have been specific variations of the group habitus in which $\mathrm{A}$ and $\mathrm{B}$ had been socialized:

Since the history of the individual is never anything other than a certain specification of the collective history of his class or group, each individual system of dispositions may be seen as a structural variant of all other group or class habitus, expressing the difference between the trajectories and positions inside or outside the class. 'Personal' style, the particular stamp of marking all products of the same habitus, whether practices or works, is never more than a deviation in relation to the style of a period or class... (Bourdieu, 1977: 86)

As a result of this thread, it often happens that, in Bourdieu's discourse, habitus itself seems to act and interact, instead of people with a given habitus doing so in a meaningful way.

Even including the nuances added to this stance in his later work, individual habitus continues to be derived from group habitus and from class division, rather than the other way around. Structure is seen as a pre-construction rather than as a constantly reshaped cumulative effect of the very differences in subjective meaning constructions which Bourdieu regards as peripheral variations of habitus. Evens makes a similar critique:

But as might be expected from his wholesale characterization of moral terms as 'masks,' he never does see that before it is a matter of power and production, human practice is a question of value qua value, which is to say, a question of ethics. (Evens, 1999: 4)

Here, by ethics Evens (1999) understands value, or, in other words the process of meaning endowment in human practice. Furthermore, he argues that it is only by adopting this starting point that theory can overcome the Cartesian dualism from which Bourdieu unsuccessfully attempts to escape.

Pascalian Meditations (Bourdieu, 2000), like A Theory of Practice (1977) in its first part, is one of the volumes where Bourdieu places more emphasis on agency, strategies of social mobility and people's wills. However, in his account of the capacity for anticipation, for instance, he insists on how this capacity is shaped by our familiarity with social practice, by our knowledge of the immanent tendencies of the field and by how our objective conditions shape our aims and desires. While these are indubitably valid remarks, 
Bourdieu implicitly assumes an underlying direct and deterministic link between familiarity with social practice and social structure. In making this step, he goes back into the initial objectivist vein. My claim is that the hermeneutic mechanisms through which social practice becomes meaningful are conditioned, but not straightforwardly determined by belonging to a social stratum.

While making the contours of social structure more visible, this perspective solidifies concepts that are meant to capture social life in its fluid form. The habitus of a certain class is an ideal typical construct emerging from and referring to the communalities developed by people with similar capital accumulations; despite the extrinsic character it may develop over time, its subjective grounds remain very relevant. The same goes for social relations which are not particular ways of filling a fixed structure. Social space is not occupied, but made. Despite appearing objectified, we must keep in mind these relations and the ways in which they are lived and interpreted are the structure. Attempting to move beyond the messiness of social reality for the sake of systematization is an effort of abstracting the 'unabstractable'. Organization must be found within, not beyond the messiness of empirical social relations. In this vein, I maintain, with Bottero and Crossley (2011), that it is more productive to study social relations in their empirical unfolding, not as manifestations of an objectified form.

From here it follows I regard social capital not as an asset of the occupant of a certain position by virtue of his/her connections with occupants of other positions in the field. Rather, social capital is an asset of a social actor by virtue of his/her connections with other social actors. Their role in the construction of the social field is of course very significant. However, when not viewing actors as embodied habitus, they gain complexity; they engage in hermeneutic processes and seek to make sense of their experience. Meaning making is also class dependent and learnt through socialization, yet some variations, unique life course, unpredictability of reflective mechanisms cannot be traced back to crystallized group habitus. From this standpoint, the construction of social capital will be discussed through the lens of engaging in social relations, understanding them, managing the other's evaluations and expectations in relation to them, estimating relational closeness, assuming an image about the broader social field a person and his/her contacts are part of and considering the links oneself and others have woven within that field.

To be clear, my stance does not reflect a denial of the importance of social structure in conditioning the configuration of the social field, the habitus or the unfolding of social relations. Like Bourdieu, I hold that there is nothing people do, think, or feel that is 'uncontaminated' by the social. Nevertheless, unlike Bourdieu, I understand habitus as less organized; the social construction of subjects implies a variety of influences, experiences associated with people or typical behaviours of different classes, a wide array of lived situations which have been constructed as meaningful according to different logics. Consequently, despite the commonalities between those who have similar accumulations of cultural capital (for instance), the uniformity of their habitus and the uniformity of how that habitus translates into the experience of everyday life must not be overestimated. While a flattening of differences between people with similar habitus can be argued to capture patterns of class in a more pronounced way, it also tends to overlook the fact that no human being is only a representative of a particular social class/group/ community/gender and nothing more. 


\section{Imagined social capital}

The notion of imagined social capital was introduced by Quinn $(2005,2010)$ in conjunction with the concept of symbolic community as an alternative to learning communities and communities of practice, which are at the centre of the dominant discourse in adult education. The author elaborates on the risks of learning communities and communities of practice to promote homogeneity and to perpetuate exclusion. Imagined social capital, on the other hand, escapes this logic by allowing social actors to be part of communities they themselves create. Namely, according to Quinn (2010: 68), 'imagined social capital is the benefit that is created by participating in imagined or symbolic networks'. Thinking of Bourdieu's later views, Quinn's notion can be linked to the above-mentioned topic of Pascalian Meditations - the calibration of people's aims according to their estimation of the means of achieving them, or the so-called causality of the probable. When one constructs themselves as part of an imagined community with a given symbolic capital, this imagined belonging can become a resort for resistance and re-envisioning, as Quinn (2010) points out. Through her theoretical argument and empirical exploration, the author highlights how the bonds that constitute social capital need not be factual in order to be effective.

This is an idea which I believe is very important, fundamental in understanding social capital and it is one that this article heavily draws on. The relevance of imagined social capital resides in how social actors envision and interpret their belonging to a network on the basis of a typified view of the characteristics of the members of that network, rather than by virtue of a factual bond with them. On the one hand, this shows one of the ways in which subjective constructions of meaning may not coincide with what Bourdieu views as the objective structure of the social field and how an agent can assimilate influences from his/her social life in order to generate practices which were not embedded in the habitus of the group in which he/she had been socialized. On the other hand, it draws attention not only towards how subjective meanings escape the pre-established habitus of an objective position in the social field, but also towards how these subjective meanings promote a reshaping of the objective structure. To illustrate, one of the examples Quinn (2010) uses is the importance of clothing for homeless people. Elaborating on interview excerpts, she reveals how the very fact of wearing a suit can develop for the homeless person an imaginary of belonging to a different social network than the one constituted by his/her actual social bonds, which makes them more open towards finding a job. Other examples that come to mind include imagined belonging to communities of people with similar life experiences (eg victims of domestic abuse), hobbies, fetishes, or illness. Yet, as Quinn (2010) herself illustrates, there is no intrinsic positive value associated with imagined social capital. The same mechanism of attaching oneself to an imagined community can also act as a setback in a variety of cases.

This being said, when faced with structural problems of the type Bourdieu talks about, imagined social capital is a limited resource in the struggle for social mobility. Imagined social capital functions, as I mentioned above, in reshaping the will power of subjects, their estimation of the probable and possible unfolding of social situations, but it does not affect the estimations made by others about one's social capital. I might feel I belong to an imagined community, yet the fact that I find that empowering does not mean people 
who come in contact with me will estimate my imagined social capital or will make sense of me according to it.

The evaluation of the other is not only important with respect to graspable outcomes and to challenging the existing objective - or, in a Berger and Luckmann (1966) vein, I would say objectified - social structure. The other also has a direct impact on one's own imagined social capital, through what Cooley (1902) has famously named 'the looking glass self'. At its core, this concept, as well as Cooley's theory in a wider sense, deals with the incorporation of our imaginaries about the others' evaluations of us in the construction of our own self-image. Not being recognized as having a certain imagined social capital (eg 'You don't even know who these people you feel so close to are') can add a serious component of confusion or anxiety to imaginaries of belonging. Following these considerations, I believe it is important to enrich the notion of imagined social capital by exploring the dimension of the others' imaginaries about a social actor and the ways in which they connect to his/her own imagined social capital.

However, imagined social capital has a different composition when understood both from the perspective of the others with whom the subject comes in contact. For Quinn $(2005,2010)$ the imaginary aspect of the type of social capital she describes originates in the subjective constitution of belonging to a symbolic community. In other words, the subject might feel connected to that network by virtue of what he/she interprets as common features/ experiences/ hobbies/ class/ lifestyle etc., without the need for an actual social bond with given individuals.

In the case of imagined social capital others construct around a social actor, the imaginary includes an outsider's look over a network of people who have something in common with the subject, but with whom the subject is assumed not to share a link. Yet, more than being imagined as a community, the similarity between people, seen from the perspective of an outsider, is a ground for typification. I will illustrate this by using a classic example of ethnic belonging. Being a member of a certain ethnic group is a fact which can encourage the development of one's imagined social capital, as Quinn would argue. As a result of the symbolic value placed on ethnic belonging, the subject would feel bonded with those who share it. From the outsider's perspective, the ethnic community that one experiences as imagined social capital and the symbolic bonds that feed on that imaginary are absent. Thus, instead of constructing a community and a sense of belonging, he/she will construct ethnicity as a type with a series of characteristics.

Despite these premises, there is a different type of imagined social capital developed mostly in the interpretations of others. However, the imagined character does not reside, in this case, in the relation with symbolic communities, but in the estimation of the actual network of bonds of the other. From this perspective, imagined social capital refers to the number or quality of bonds which one social actor believes the other might have. There are several aspects which favour the development of one's social capital as an imagined construction in the mind of another social actor. Namely, the status of being an outsider relationally speaking to particular social bonds and the lack of physical co-presence are amongst the main factors contributing to this phenomenon.

In a small-scale traditional pre-free market community, it is easy to understand how people would keep track of each other's social capital: they knew who got along with whom, who was related to whom, whose position made them respected or protected by 
an institution. In a sense, all the members of the community had an insider status on the bonds of that community, at least within certain limits.

In late modern society, that is no longer the case. The changes occurring with the industrialization, urbanization and emergence of capitalism were well documented by authors from Tönnies (1963) and Weber (1930) to Polanyi (1957) or Sennett (1977). One of the consequences of these changes was the separation of different aspects of everyday life and the dissolution of the old organization of communities. In terms of social capital, I would add, this makes the bonds one social actor has less accessible to and measurable by others with whom he/she is bonded. One's work colleagues do not know that person's old class mates or his/her hiking friends. Neither do they know the extent to which that person is connected with people of a particular socio-economic status, or even whether he/she is friends with the boss. Thus, I believe a very important element that needs to be taken into account when we talk about late modernity is not only the isolation of individuals, but also the isolation of bonds. Networks of bonds still exist, but they typically circumscribe areas of one's life that are not interconnected. One outcome of this situation is the construction of an imaginary about the unknown part of the other's life. If the estimation of other types of capital does not change from one area to another, the one of social capital does. For instance, if I am friendly with my work colleague, I might be able to estimate their economic and cultural capital by interacting with them, and that estimation would also be valid for the areas of their life of which I am not aware. Social capital, on the other hand, needs to be imagined in spite of not knowing to whom and how strongly the colleague is connected.

The outsider status one person has in the other's life and in their bonds is strongly rooted in the issue of non-copresence which Schütz $(1964,1967)$ extensively talks about. While Schutz's claims about co-presence as a necessary condition to interpreting the other in subjective terms can be critically re-examined (Ivana, 2016), I do consider the theme of sharing the same world within reach to be crucial in a debate on social bonds. More precisely, in the context of this article, the frequent separation between the worlds within reach of bonded social actors encourages imaginaries about the absent other. The other's social relations, which are not graspable by me in my world within reach, come to construct my imaginary of their social capital.

In this context, the issue of the accuracy of one's imagination about the other's social capital becomes less significant. The actual social bonds someone has will be a great resource for social mobility or for accumulation of other types of capital in immediate ways; social capital has the tendency to reproduce and increase itself. Yet, imagined social capital may be just as beneficial as real bonds in generating more social capital. Through its consequences on the interpersonal connections established in everyday life, imagined social capital is very real and quite powerful.

People often experience life in terms of social inequalities and interpret it accordingly. They will have an estimation of the social field and how they contribute to it. They will also see others as subjects and expect them to have meaningful readings of them according to different axes of capital and they will go out of their way to ensure they are read as they wish to be read. This includes both trying to gain various capitals and trying to display them. When referring to social capital, the gain comes from associations with others of higher standing, which inherently involves identifying those of higher standing and 
seeking closeness with them. This identification must rely on imagined social capital. In light of this process, those who are imagined to have considerable social capital will be sought after, socially praised and they will benefit from the others' desire to associate with them in creating more social bonds. When the imagined social capital constructed around someone is solid enough, the actual bonds resulting from it are not only more numerous, but also established with people with better 'positions' in the social field. The question of whether the initial imagined social bonds on which the estimation of social capital was based were reflecting existing bonds has no bearing on this process.

Above, I mentioned the fragmentation of social bonds and the lack of a common world within reach as factors which favour the development of imagined social capital. Another such factor is the partial disembodiment of social capital. Both Bourdieu and Coleman talk about the fact that while social capital is a variable describing individuals, it also has a relational character. It is a sum of actual and potential benefits a person has by virtue of his/her connection with others. Thus, while cultural capital, for instance, comes with immediately observable embodied characteristics, social capital is not as easy to capture. In certain aspects, social capital can be assumed as proportionate with other capitals (eg someone coming from an upper-middle-class family can be assumed to have good contacts, if only by virtue of their background). Furthermore, popularity, easiness of interaction, authority and humour can account for enough symbolic capital to make someone accepted in a different class than his/her background would allow or isolated at the periphery of the class to which they belong. In other words, a holistic view on the other capitals with symbolic value that one has, will offer cues in constructing an imaginary about their social capital. Yet this is an approximation and there will always be a doubt about whether all that is symbolically relevant has been considered in the estimation of social capital (eg maybe he is better connected than he seems. Who knows what people see in him?). Since social bonds are created around a variety of criteria, there is little in the body, movement, way of expressing themselves of the others which enables a definite reading of their social capital.

One outcome of this sum of factors is the credibility of one's depiction about his/her social capital, the unfolding of their bonds and the experience of their life when they are not in the other's world within reach. This leads me to another level of imagined social capital: the induced imaginary. Until this point, I have presented a person's imagined social capital as a construct in the mind of the other, independently of the actions of the one whose life is under scrutiny. I have chosen to do so because I believe these imaginaries can and often do exist independently of what the person whose social capital is evaluated does. However, since, as mentioned above, there are benefits not only to gaining, but also to displaying capital, it is easy to conceive of someone intentionally putting effort into building an imagined social capital in the eyes of others.

Referring to capital in general, the practice of deliberately acting to construct in the mind of the others an estimation of one's level of capital which they themselves do not believe they own is the core of imposture. Referring to imagined social capital, this type of imposture is easier to achieve, if we consider the premises exposed throughout the article. Given the lack of embodiment of social capital and its foundation upon a variety of capitals which can be thought to have symbolic value, even unlikely social bonds can be accepted as possible. Based on this hypothetical possibility in the mind of the other, 
one can elaborate ways of filling in the gap of non-copresence with the idea of various bonds. As deceiving as it may appear, this practice can materialize in brief mentions of one's friend who is working in a job of high responsibility, in a photo with a celebrity, in sharing something which denotes closeness to someone the other regards highly or complaints about being tired after weekends spent with social activities. On a terrain of lack of information about the network or community from which the subject draws his/her social capital, and on a terrain where despite estimations based on other capitals, social capital still has an unknown component, these constructions are likely to remain unquestioned. The typical outcome is a construction, in the eyes of the outsider/observer, of an imagined capital which is not only less shaped by other types of capitals with symbolic value, but which is also shaping estimations about other capitals. Thus, taking the example of prestige in the academic field, a person may, upon meeting a colleague, assess his/ her social capital or the basis of his/her cultural capital, which is easier to observe in social interaction. However, if that colleague succeeds in constructing a credible image of his/her social capital in the eyes of his/her casual evaluator, social capital will not only become less influenced by cultural capital, but may also have an effect on it (eg, This person has great contacts. They must be well prepared if they are appreciated by so many). In this sense, imagined social capital contributes to configuring the social field. When others start from the premise that one plays a certain part, in structural terms, in the social organization with which they are familiar, that person will benefit from all the advantages and disadvantages of who he/she is thought to be, or to use Bourdieu's conceptual framework, of the position he/she is thought to occupy. Thus, one route towards gaining privileges or power objectively speaking is by constructing them subjectively. Although I have described this above as imposture, it is, in the case of social capital, the type of imposture where social sanctions are very improbable. Since social capital relies on bonds, on interpersonal connections, which are by default fluid, changing and interpretable, in creating an imaginary about those bonds to others, reliability and verifiability are less central than in most segments of one's social life.

Assuming that the imaginary about social capital is intentionally constructed not to reflect 'objective' social capital, the practice of constructing this imaginary and feeding it to others can be regarded as a form of resistance, since it breaks the order of the established class system. Yet, it does so by drawing on the weaknesses of the system and by adapting to its logic, not by challenging its foundations. From this perspective, I regard the construction of imagined capital as a compliant rather than disruptive means of achieving social mobility. To be clear, my claim is not that imagined social capital leads directly to upwards social mobility, but that it increases the likeliness of developing more and better connections, which is a factor contributing to social mobility.

At the same time, Bourdieu's observations about social capital being strongly dependent of social class and background are as valid as ever. And, if it is challenging to estimate which other types of symbolic capitals one might use in developing social capital, it is significantly easier to estimate which lacks of symbolic capital will be unforgivable in which social environment. In other words, not thanking a host for dinner, or not knowing how to use a fork still mark a deficit in capital that cannot be overcome by constructing imagined social capital. Moreover, in these examples, it is almost impossible to construct imagined social capital in a credible manner. Before the estimation in the 
other's eyes has any outcome, the imaginary one is trying to promote needs to be at the very least plausible, if not probable, for his/her evaluator.

This means that imagined social capital is more likely to have an impact on a limited scale of mobility. Imagined social capital is not a functional mechanism for dramatic upwards movement in the social hierarchy. Since it relies on shaping how the subject is appraised by others, this type of capital must encourage a way of making meaning that is not openly challenging institutionalized meaning constructions. If someone who is typically read as working class attempts to construct imagined social capital around him/ herself by pretending they have a strong bond with several of the richest people in the country and they attend their gatherings, it is very probable they will fail. This happens because the meaning they are trying to convey is not slightly different, but decidedly opposed to the habitualized understanding of a person who 'looks working class' and 'acts working class'. Imagined social capital can, on the other hand, be used as a systematically induced nuance in the typical meaning construction. To continue the example above, if the same person who is typically read as working class depicts moments of non-copresence as time spent with a few middle-class friends, gradually introducing, but not overstating closeness their chances of success will increase significantly. So, from here it follows not only that acquiring imagined social capital is a gradual process, but also that it requires a fine understanding of existing institutionalized and even moderately habitualized meanings. Of course, since meaning constructions tend to have certain communalities between people with similar levels of capital and similar socialization as part of a group, the actual mechanisms of creating imagined social capital would vary according to whose imaginary one is trying to impact upon. In Bourdieu's words, the habitus of each social class has different particularities in understanding the social field and the positions of given individuals, so the ways of constructing imagined capital must vary according to the habitus of the evaluators.

In other words, I consider it important to point out that imagined social capital, the evaluations of the others and the way in which these evaluations are co-constructed in everyday life interactions are not presented here as an alternative to the material background on which Bourdieu builds social structure. Rather, they are presented as a complementary element meant to highlight the inextricable unity between structures and lived social relations and their meaning. While all capital can be reduced to economic capital, attempting to do so is misleading as it obscures other important dynamics which structure the social world.

\section{Conclusion}

The aim of this article is twofold. Firstly, it argues for a phenomenologically influenced conceptualization of social capital. Secondly, in light of this conceptualization, it proposes an expansion of the notion of 'imagined social capital' to incorporate the interpretative processes of everyday life and the issue of otherness.

While a variety of aspects in today's social theory are founded on the remarkable depth of Bourdieu's thought, these influences are often rooted in different parts of his work. In the theory of social practice the concerns about the objectivist accents in his oeuvre have been addressed in a compelling manner; scholars working with the conceptualization of 
habitus and of social structure are constantly discussing the role of agency and cognition. The notion of social capital, however, is perhaps one of the areas of Bourdieu's work which has not only been embraced without a critical reflection about its objectivist background, but an area in which that objectivist background has been applauded. Despite the fact that important parts of the ongoing discussions about Bourdieu's work can easily be interpreted as touching upon social capital, the implications of these debates on social capital have yet to be explicitly explored. In this context, the current article questions the notion of social capital in several of its basic assumptions: that it is (1) measurable, (2) independent of subjective estimations of it and (3) universally recognizable by social actors in its objective character. Drawing on general scholarly considerations on Bourdieu, I advocate for an understanding of social capital which accounts for the meaning constructions through which it is experienced and evaluated.

In the vein of a phenomenological perspective on social capital, I turn to the notion of imagined social capital, which has previously been used in the literature to refer to the link of social capital with self-identity and belonging to imagined communities. Whereas this is an important step in challenging the objectivity of social capital, I maintain this perspective must necessarily include the relation of the subject with the other. At this point, there is a shift from social capital as imagined by oneself about oneself, to the imaginary about the social capital of the other, which closes the circle of the argument, by returning to the hermeneutics of social practice in everyday life. Through bringing the focus on the importance of reciprocal interpretative processes in the development of social networks and communities, the article insists on the underexplored but tangible effects of imagined social capital on Bourdieusian objective social capital.

\section{Funding}

The author(s) received no financial support for the research, authorship and/or publication of this article.

\section{References}

Adams, M. (2006). Hybridizing habitus and reflexivity: Towards an understanding of contemporary identity? Sociology, 40(3), 511-528.

Alexander, J. (1994). Fin de siècle social theory. London: Verso.

Atkinson, W. (2010). Phenomenological additions to the Bourdieusian toolbox: Two problems for Bourdieu, two solutions from Schutz. Sociological Theory, 28(1), 1-19.

Berger, P. L., \& Luckmann, T. (1966). The social construction of reality. New York, NY: Anchor Books.

Bottero, W., \& Crossley, N. (2011). Worlds, fields and networks: Becker, Bourdieu and the structures of social relations. Sociology, 50(1): 99-119.

Bourdieu, P. (1977). Outline of a theory of practice. Cambridge: Cambridge University Press.

Bourdieu, P. (1985). The forms of capital. In J. G. Richardson (Ed.), Handbook of theory and research for the sociology of education (pp. 241-258). New York, NY: Greenwood.

Bourdieu, P. (1990). The logic of practice. Cambridge: Polity Press.

Bourdieu, P. (2000). Pascalian meditations. Stanford, CA: Stanford University Press.

Coleman, J. S. (1988). Social capital in the creation of human capital. American Journal of Sociology, 94(Supplement: Organizations and Institutions: Sociological and Economic Approaches to the Analysis of Social Structure), S95-S120. 
Coleman, J. S. (1991). Prologue: constructed social organization. In P. Bourdieu \& J. S. Coleman (Eds.), Social theory for a changing society (pp. 1-14). Boulder, CO: Westview Press.

Cooley, C. H. (1902). Human nature and the social order. New York, NY: Scribner.

Croll, P. (2004). Families, social capital and educational outcome. British Journal of Educational Studies, 52(4), 390-416.

Crossley, N. (2001). The phenomenological habitus and its construction. Theory and Society, $30(1), 81-120$.

Crossley, N. (2008). (Net)working out: social capital in a private health club. British Journal of Sociology, 59(3), 475-500.

Crossley, N. (2009). The man whose web expanded: Network dynamics in Manchester's postpunk music scene 1976-1980. Poetics, 37(1), 24-49.

Evens, T. M. S. (1999). Bourdieu and the logic of practice: Is all giving Indian-giving or is 'generalized materialism' not enough?' Sociological Theory, 17(1), 2-31.

Gowan, T. (2010). What's social capital got to do with it? The ambiguous (and overstated) relationship between social capital and ghetto underemployment. Critical Sociology, 37(1), 47-66.

Halle, D. (1993). Inside culture: Art and class in the American home. Chicago, IL: University of Chicago Press.

Ivana, G-I. (2016). Present contemporaries and absent consociates: Rethinking Schütz's 'we relation' beyond here and now. Human Studies, Epub online first 18 February 2016. DOI: 10.1007/s1074601693819.

Jenkins, R. (1992). Pierre Bourdieu. London: Routledge.

King, A. (2000). Thinking with Bourdieu against Bourdieu: A 'practical' critique of the habitus. Sociological Theory, 18(3), 417-433.

Kogler, H. (1997). Alienation as an epistemological source. Social Epistemology, 11(4), 141-164.

Lamont, M. (1992). Money, Morals and Manners: The culture of the French and American upper class. Chicago, IL: Chicago University Press.

Lareau, A. (2002). Invisible inequality: social class and childrearing in black families and white families. American Sociological Review, 67(5), 747-776.

Morrow, V. (1999). Conceptualising Social capital in relation to the well-being of children and young people: A critical review. Sociological Review, 47(4), 744-765.

Parsons, T. (1957). The social system. New York, NY: Free Press.

Polanyi, K. (1957). The great transformation. Boston, MA: Beacon Press (original work published 1944).

Portes, A. (1998). Social capital: Its origins and applications in modern sociology. Annual Review of Sociology, 24, 1-24.

Putnam, R. (2000). Bowling alone: The collapse and revival of American community. New York, NY: Simon and Schuster.

Quinn, J. (2005). Belonging in a learning community: The re-imagined university and imagined social capital. Studies in the Education of Adults, 37, 4-17.

Quinn, J. (2010). Learning communities and imagined social capital. New York, NY: Bloomsbury Publishing.

Schütz, A. (1964). Collected papers, Vol. II: Studies in social theory. The Hague: Martinus Nijhoff.

Schütz, A. (1967). The phenomenology of the social world. Evanston, IL: Northwestern University Press.

Sennett, R. (1977). The fall of the public man. Cambridge: Cambridge University Press.

Smith, S. S., \& Kulynych, J. (2012). It may be social, but why is it capital? The social construction of social capital and the politics of language. Politics and Society, 30(1), 149-186. 
Tlili, A, \& Obsiye, M. (2014). What is Coleman's social capital the name of? A critique of a not very social capital. Critical Sociology, 40(4), 551-574.

Tönnies, F. (1963). Community and society, translated from the German by CP Loomis. New York, NY: Harper and Row (original work published 1887).

Weber, M. (1930). The protestant ethic and the spirit of capitalism. London and Boston: Allen and Unwin (original work published 1905).

Widick, R. (2003). Flesh and the free market: (on taking Bourdieu to the options exchange). Theory and Society, 32(5-6), 679-723. 